Original Research Paper

\title{
Evaluation of Geometric and Environmental Parameters in Reuse of Deactivated Railway for LRV Implantation
}

\author{
Isabelle S. Sales, Gislaine Santos, Jordan H. Souza and Ana Stephan \\ School of Civil Engineering, UFJF Federal University of Juiz de Fora, Juiz de Fora (MG), Brazil
}

Article history

Received: $29-08-2017$

Revised: $30-08-2017$

Accepted: 13-10-2017

Corresponding Author: Isabelle S. Sales

School of Civil Engineering, UFJF Federal University of Juiz de Fora, Juiz de Fora (MG), Brazil

Email: isabelle.sales@engenharia.ufff.br

\begin{abstract}
A portion of the origin-destination matrix of freight transport in Brazil corresponds to the railway mode; however, a small part of the matrix of passengers is represented by the modalities that use railway lines. The country has an extensive railway network, mainly in the southeast, but some parts are deactivated. This article aims to present a study of the possibility of implementation of a Light Rail Vehicle (LRV) on a stretch that is not in use, since the superstructure has a long useful life and therefore the railroad can be reused for a new use. For this analysis, the geometric parameters of the radius and velocity of the track and the environmental parameters of the domain range, such as the altimetry, amplitude, slope and susceptibility to sliding of the soil according to the Shalstab model, were used.
\end{abstract}

Keywords: Light Rail, Georeferencing, Susceptibility to Soil Sludge, Shalstab

\section{Introduction}

According to the National Transportation Confederation (CNT, 2013) in Brazil, rail transport represents approximately $20 \%$ of the cargo origindestination matrix but only just less than $2 \%$ of the passenger origin-destination matrix. Most of the Brazilian rail network is concentrated in the southeast region, in the states of São Paulo and Minas Gerais and mainly operates under the private concessions system. The National Land Transport Agency (ANTT) regulates the infrastructure and public transport services for passengers and freight, while the National Department of Transport Infrastructure (DNIT) is responsible for the planning, study and construction of new railroads.

The railway mode is characterized by having a high cost of implementation and maintenance but has high energetic effectiveness. It can be said that in comparison to the road transport mode, social costs due to accidents and the emission of pollutants by locomotives (if compared to the amount of vehicles that would be required to carry the same load per train) are smaller. In addition, the life time of the railway components varies, on average, from 10 to 40 years for a railroad car (CNT, 2013).

The main advantage of railroads is that they facilitate the transportation of heavy loads over long distances, since this mode is more economical under these conditions. When it comes to urban passenger transport, rail transport has several modalities that, despite not having precise conceptualizations, differ mainly in terms of the capacity of transport. These modalities include metropolitan trains, monorails, subways and Light Rail Vehicles (RLVs) (CNT, 2016).

The railway mode is an important part of the nation's transport matrix and, therefore there is considerable interest in continuous investments in the railway network and studies from the perspective of analyzing, improving and re-routing the tracks in a country of continental proportions are important.

Considering the advantages of this mode, this article aims to present a case study of the railway section between the cities of Vicente de Minas (Minas Gerais) and Angra dos Reis (Rio de Janeiro), which, although it is listed as active in the official information provided by the government, is not in operation. The cities covered by these kilometers of railroad are located in the southeastern region of Brazil and although it would be expensive, the superstructure could be reused for decades and this is seen to be important.

The activation is proposed through the implementation of the LRV to transport passengers between the cities through which the railway line passes through an analysis of the geometric and environmental parameters of the railway.

For the geometric study, the radius of the track curves give the speeds that can be reached safely and allow comparison with the design speeds of the light vehicle on rails. For the environmental analysis, the domain range is considered for each side of the railroad according to the 
altimetry, amplitude of the relief, slope and soil's susceptibility to sliding determined by the Shalstab model.

\section{Literature Review}

\section{History of Railways}

Society has undergone profound changes since the eighteenth century with the Industrial Revolution beginning in Britain. According to Hobsbawn (1977), this revolution was the most important event in the history of the world, at least since the invention of agriculture and cities because, according to Finger (2013), the changes not only affected labor relations but also altered technological development as well as the daily habits and structures of the new urban centers.

Due to a combination of factors such as the concentration of large amounts of capital in the hands of a bourgeoisie that was ascending in society, England was the pioneer in these transformations. According to Hobsbawn (1977) and Finger (2013), railway technology emerged in the scenario of growth of the textile industry and the later steel industry and was a consequence, not a cause, of industrial development, as more efficient and rapid means of locomotion of raw materials, especially charcoal ore, a source of energy widely used in the period, were sought.

The construction of railroads involved the development of the steel industry and participated in the large context of transport systems that included ports and ships for commercial transactions between countries. Still, according to Finger (2013), the use of trams and trains to replace wagons was popularized, which evidently impacted the environment due to the use of fossil fuels and the increasing exploitation of resources such as iron.

International treaties have been proposed to establish the British steel industry and Finger (2013) cites them as "model rail packages for technology export" as this model agglutinated the drafting, construction and operation of railways by British companies in the former colonies. The consequences were changes in the urban features, since the implantation of the whole railway system led to the construction of tunnels, viaducts and stations, encouraging research on new materials for use in building constructions.

Brazil was one of the colonies that was explored and "the process of implanting the lines also helped to clear the territory" (Finger, 2013), altering the landscape by replacing nature with iron and wood, symbolizing the progress that, according to Lima (2003), the Brazilian elite sought as a response to the "Brazilian backwardness" and internal political problems.

In Brazil, from 1850 onwards, tax exemption laws were enacted for companies that built railroads nationwide (Law No. 641, which offered a guarantee of interest on the capital invested in the Brazilian railways) and a result was the growing conquest of the Brazilian market by foreign industries (Luz, 1978).
According to the Institute of National Historical and Artistic Heritage, the position taken by the government aimed the entry of foreign capital and also linking agricultural and mining centers to ports. The first railway was built in Brazil in 1854 and was about $14 \mathrm{~km}$ in length, connecting Porto Mauá to Fragoso in Rio de Janeiro.

According to Picanço (1887), until September of the same year, the total length of railroad in use was 8346 $\mathrm{km}$ and, according to the Brazilian Institute of Geography and Statistics (IBGE, 1954), in the period between 1854 and 1889, the annual growth of railroads was about $266 \mathrm{~km}$.

Proclaimed as a Republic in 1889, the government began to control the investing companies and accepted offers according to their interest in order to enable greater integration of the network. However, due to the economic damage caused by World War II, railroads brought monetary damages to companies, so the railroads were moved to state control with the aim of recovering these costs. It is estimated that between 1890 and 1952 the growth of the railways was $442 \mathrm{~km}$ per year (IBGE, 1954).

In 1957, the Federal Railroad S.A. (RFFSA), which brought together state-controlled railroads, emerged. In 1992, just under 40 years since its inception, RFFSA was included in the National Privatization Program (PND) by Concessions Law 8987/95. State capital was already exhausted with the expenses of managing the railways and, according to the National Land Transport Agency (ANTT), the PND aimed to improve resource allocation, increase operational efficiency, foster market development and improve the quality of services.

RFFSA was finished in 1999 through concession processes assigned to private companies for 30 years through bids. Seven concessionaires (Novoeste S.A, Centro-Atlância S.A, MRS Logística S.A, Tereza Cristina S.A, América Latina Logística do Brasil SA, Companhia Ferroviária do Nordeste and Bandeirantes S.A) started their operations, which covered a total of $25600 \mathrm{~km}$.

\section{Light Rail Vehicle}

A Light Rail Vehicle (LRV) is a rail mode for passenger transportation and, according to the CNT (2016), it is a modality of medium-capacity transport that aggregates several cars in a train. LRV is able to circulate in limited road or not and it is characterized by having light circulation and low shake, being able to have a low floor at street level with rail integrated, allowing to share the road with the cars. LRV uses automotive or electric traction (electric traction is more usual).

The LRV is a mode that is more attractive as it allows visual proximity between passengers and the environment (CNT, 2016). Ferbrache and Knowles (2017) state that LRV is a tool that brings social, economic and environmental benefits, because it has less noise and fewer bumps compared to conventional buses 
and trains, as well as propelling the symbolism of a modern and technological system that adds value to the cities that have implemented it.

According to Vuchic (2012), LRV is not affected by traffic congestion and can be applied in different locations and situations: for low-speed travel over short distances, for higher-speed travel in suburban sections and for urban feeders to the subway, or it can even serve as the main transportation network of a city.

According to Cao (2013), since transport affects the quality of life and feelings of wellbeing, the LRV is associated with feelings of satisfaction regarding travel by its users. This can be explained by the fact that the LRV can connect residential districts to institutional and commercial centers in a way that is more comfortable for the inhabitants.

Vuchic (2012) states that a LRV, because of its diversity of deployments, provides better service than buses for a smaller investment than the subway and is ideal for people with reduced mobility when deployed at street level. Cao (2013) affirms that accessibility is a fundamental objective of railway investments.

According to Motta (2013), a LRV can be driven manually or automatically and can be pulled by air, rail, batteries, or fuels such as diesel, biodiesel and alcohol. This is in agreement with Alouche (2012), who, in view of its definition, shows how diversified the LRV can be, since the term "light vehicle on rails" defines the vehicle but not its mode.

In Brazil, there are still few light vehicles on tracks. The main examples of LRVs are in Rio de Janeiro, where they were partially introduced in 2016 without the use of overhead power lines, with $28 \mathrm{~km}$ connecting the Port Region to the Center and in São Paulo, where they were inaugurated in January 2017, with $11.5 \mathrm{~km}$ connecting Santos and São Vicente, powered by electricity.

Other examples are subways, which can be classified as LRV by diesel traction, according to the definition given by the CNT (2016) and can be found in the metropolitan region of Fortaleza, in the metropolitan region of Cariri and in the city of Sobral, all in the state of Ceará. There are still other cases where LRV is used, but because the lines are not segregated in the central areas and have enough crossing points with vehicles and pedestrians, the systems are considered as trains; these systems are found in Maceió, João Pessoa and Natal (CNT, 2016).

\section{Operational Characteristics of the LRV}

In the present study, the following LRV operating characteristics are considered: the operating speed and minimum radius in a horizontal curve with superelevation.

According to Oliveira (2009), the average speed of a light vehicle on rails is 25 to $40 \mathrm{~km} / \mathrm{h}$. At peak travel times the speed is $28 \mathrm{~km} / \mathrm{h}$ on average (Alouche, 2007).
For the purpose of comparison, a speed of $40 \mathrm{~km} / \mathrm{h}$ is considered in this study.

The minimum horizontal curve radius is $30 \mathrm{~m}$ for an urban RLV and $80 \mathrm{~m}$ for a regional RLV. The case study is of a regional RLV, so the minimum radius considered is $80 \mathrm{~m}$.

\section{Concepts}

\section{Geometric Characteristics of the Railway}

According to Decree No. 7929 of December 2013, the domain strip is "the portion of land with a minimum width of $15 \mathrm{~m}$ on each side of the railway axis, without prejudice to the dimensions stipulated in the current technical norms and regulations, or defined in the project of expropriation or implementation of the respective railroad". It is understood, therefore, which domain strip is the expropriated track for construction of the railroad, composed of infrastructure and superstructure (De Carvalho, 1973).

Infrastructure means the cuts, embankments, tunnels and bridges, which is the works below the earthwork to the bed. In turn, the superstructure consists of the ballast, sleepers and rails, that is, the visible parts of the railway line that support the rolling surface of the railway and suffer wear.

According to De Carvalho (1973), the bed is the part of the platform that supports the ballast and it consists of a layer of crushed rock that supports the sleepers. The sleepers are the structures that transmit the forces received by the vehicles to the ballast, support the rails and keep the gauge (the distance between the rails) invariable.

In order to reduce investment and increase the return of a railroad, technical characteristics vary according to terrain, since excavations are costly (Antas et al., 2010). According to Amaral (1957), the terrains on which the railway lines are constructed are classified according to the slope, which is the ratio of altimetric distance to planimetric distance, usually expressed as a percentage (Mauro and Lollo, 2004).

Thus, the land can be flat, when the line with the highest slope has a transverse slope equal to or less than $8 \%$, or can have a slope of 8 to $20 \%$ or a slope greater than 20\% (Amaral, 1957).

Once the railway line has been defined, there is a guide or design speed, which is the maximum speed at which the train can travel safely (Antas et al., 2010). The curve radius is the radius of the arc of the circle used in the concordance between two lines (also called tangents, which are pieces of concordance between two circular curves of opposite directions) (De Carvalho, 1973).

In order to balance the effects of the centrifugal force on the horizontal curves, the outer rails are elevated so that the track is inclined by an angle such that, relative to the 
internal rail of the curve, the outer rail is defined by an elevation, the so-called superelevation (Antas et al., 2010).

According to Antas et al. (2010), the design velocity achieved on a curve of a given radius is satisfied according to Equation 1:

$$
V=4,5 \cdot \sqrt[2]{R}
$$

Onde:

$\mathrm{V}=$ The speed, in kilometers per hour

$\mathrm{R}=$ The radius of the curve, in meters

Equation (1) roughly says that the curves have a theoretical superelevation of around 160 to $170 \mathrm{~mm}$, for metric gauges, with centrifugal acceleration of $0.60 \mathrm{~m} / \mathrm{s}^{2}$.

\section{Environmental Characteristics}

Humankind's activities in the environment have grown, increasing the need for monitoring of natural resources. In the face of this reality, it was necessary, using new technologies, to create systems that would not only help in the preparation of maps but could also be used to extract data so that decisions about anthropic interventions can be made with greater security (Hara, 1998).

Geographic Information Systems (GIS) were the answer to this need and are defined as "a computer information system that capture, model, manipulate, retrieve, consult, analyze and present geographically referenced data" (Hara, 1998). These GIS systems perform operations with georeferenced data, manipulating maps that contain information of the real world entities represented there and can then be applied to environmental monitoring.

According to Hara (1998), one of the possible types of maps that can be obtained through GIS data processing is thematic maps for graphic representation. These maps are characterized by regions defined in matrix form divided into cells, which are pixels and represent specific elements of space, such as vegetation characteristics and land use and occupation.

The mathematical model used in this paper is the Shalstab (Shallow Stability Model) one, which, according to Silva (2006), combines a hydrological model with steady state flow with the infinite slope stability model. This model determines regions on slopes that can undergo shallow landslides and is used for the prediction of unstable areas where soil characteristics are not known.

For the analysis in this study, the following thematic maps were generated: altimetry, relief amplitude, slope and susceptibility to soil slip according to the Shalstab model.

The altimetry map is the base map used to generate the others. It is characterized by representing the altitude of the terrain in relation to the sea level, generating a terrain model that uses a gradient color system that represents the elevation.
The amplitude of the relief can be defined as "the difference between the altitude of a point and the altitude of the local base level" (Seabra, 2010). The amplitude maps indicate the height variation given by the difference between the maximum and minimum elevations taken in relation to sea level (if they are absolute amplitudes).

According to Araújo (2004), soil slip is a type of mass gravitational movement in which there is relative mass movement between the stable and moving portions, directed parallel to the surface. It is, in other words, the movement caused by the slopes's rupture phenomenon, leading to finite sliding of the volume of soil.

Slope maps give slope inclinations in the area of analysis. In the present study, this area is restricted to the track of the railroad $(15 \mathrm{~m}$ on each side of the center of the railroad).

\section{Methodology}

In view of the importance of railway mode studies, the objective of the present article is the analysis of the railroads, justified by the history of railroads in Brazil and the fact that the southeast is the region with the largest rail network in the country.

In order to obtain definitions and statistical data on Brazilian railroads, new data were also created using QuantumGis ${ }^{\circledR}$ and AutoCad $\AA$ software, according to Fig. 1, for the case study.

The process of vectorization of the railway network in the states of Minas Gerais, Rio de Janeiro, São Paulo and Espírito Santo, Brazil, using QuantumGis ${ }^{\circledR}$ software with the "line" feature, was started, thus defining the railroad only by multiple lines.

The maps software, on scale that it was possible to visualize the railroad lines, were used at this stage. As well as Google Maps ${ }^{\circledR}$ (Street View), which became essential for identification of stretches with asphalt and vegetation by. After the vectorization, the obtained map was compared with the map of the Brazilian Federal Railway Subsystem, which is available on the ANTT website for public viewing.

With the possession of the two tracings, it was possible to compare them, making it possible to identify stretches of railroad lines that, despite appearing in the official data of the government, are no longer used or are nonexistent. In view of this, it was decided to place greater focus to the deactivated stretches and the stretch between Angra dos Reis and Vicente de Minas, cities in the region of the southeast of Brazil, was chosen for case study.

By exporting the vectorization of the section to the case study using the software QuantumGis ${ }^{\circledR}$ for the software AutoCad ${ }^{\circledR}$, the layout with the design of the curves that best agreed with the tangents was refined. 


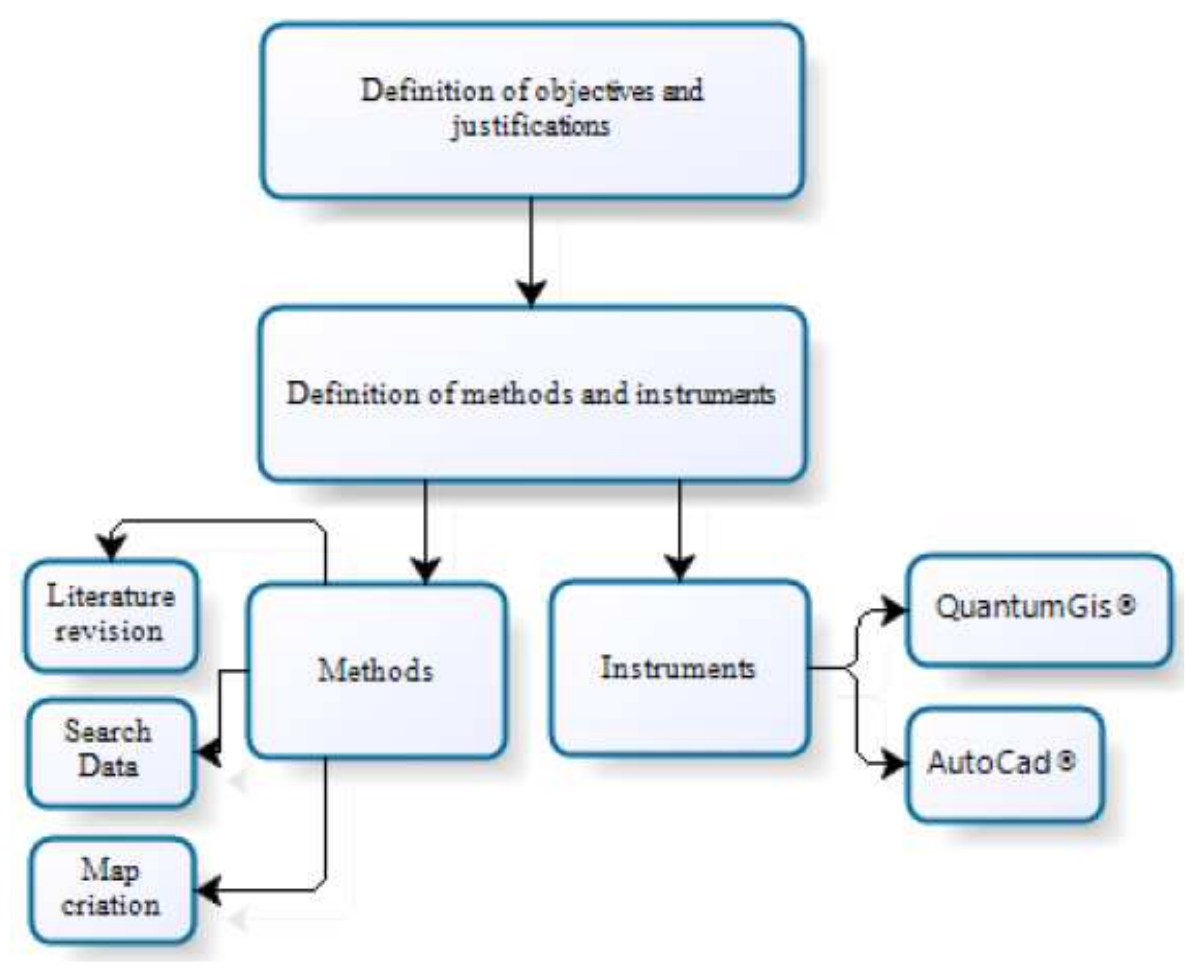

Fig. 1. General diagram of the research

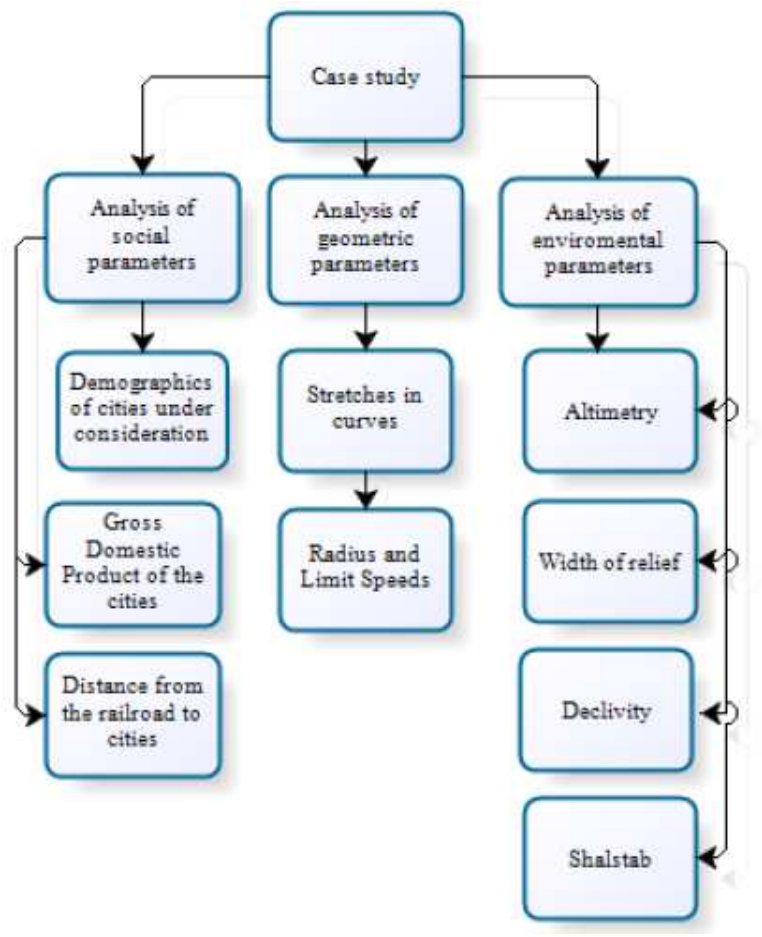

Fig. 2. Systematic diagram of the case study

The characteristics of the curves were obtained by following the QuantumGis ${ }^{\circledR}$ drawing, which was placed underneath as a template. The result of this process was generated in a spreadsheet exported to Excel ${ }^{\circledR}$ with the following information for each curve: development, center angle and radius.

Concomitant with the vectorization process, we carried out a review of the literature on railroad history the literature for railroad history and the analysis of infrastructure and superstructure concepts as well as the concepts of geometric parameters, already explained previously.

Having extracted the planimetric information, the proposed resolution for the utilization of the inactive railroad was done through the implementation of a LRV that connected the municipalities considered by the case study, since according to the previous research. This mode was interesting for the locomotion of the inhabitants of the surrounding cities, besides being an unconventional option with appreciable advantages.

From this assumption, parts were drawn for the study, seen in Fig. 2, to verify the feasibility of LRV implantation.

The geometrical parameters of the railway line were analyzed, since the aim was to reuse the lines and not to modify them (which would have a greater financial cost). Thus, the curves were prioritized and were analyzed to determine whether they conformed to the requirements for train operation (design speed and minimum radius).

Using Equation (1), it was possible to obtain the limit velocities on each curve of the railway line. These were compared with the design speed of the LRV. Further, each curve radius was compared to the minimum radius. 
In order to evaluate the social impact of the implementation of the LRV, the population and the Gross Domestic Product (GDP) of each city that the railway line would serve was estimated by the Brazilian Institute of Geography and Statistics (IBGE). The distances between the railroad and the municipalities were obtained with the use of Google Earth ${ }^{\circledR}$ software.

In the analysis of the environmental impacts, maps of altimetry, relief amplitude, slope and Shalstab were generated in QuantumGis ${ }^{\circledR}$ software.

The composition of the maps was generated with the use of the Geomorphometric Database of Brazil provided by the National Institute of National Research (INPE), which provides the Digital Model of Elevation. The data were projected from the WGS 1984 geographic coordinate system to the projected WGS 1984 Web Mercator coordinate system, allowing generation of an altimetry map, which was the basis for the construction of the consecutive maps of slope, amplitude and susceptibility to soil slip determined by the Shalstab method.

For the tabulation of areas within the domain range, the values were transformed into integers, which made it possible to generate the tables within the software. Thus, the areas were obtained, for each kilometer, from the pixels with the value of interest.

After export to Excel ${ }^{\circledR}$, the kilometers were made in sections to a better results' evaluation. Tables generated are in percentage of area, it means that in each value of altimetry, slope, amplitude, or susceptibility of sliding of the soil by Shalstab, is shown the amount of the area of the stretch (A, B, C, D, or Extension) where there is the characteristic value.

The results obtained by the three analyses (social, geometric and environmental) show the general parameters for LRV activation.

\section{Case Study}

A deactivated section was chosen for the proposed implementation of the LRV in order to reuse the already existing route. The case study comprises the railroad from Vicente de Minas (Minas Gerais) to Angra dos Reis (Rio de Janeiro).

The stretch comprises $26,336 \mathrm{~km}$ of railroad, currently belonging to the Centro-Atlântica Railway (FCA). This segment from São Vicente de Minas to Angra dos Reis is included, according to the National Road Plan, in the Estrada de Ferro 348 (EF-348) diagonal railroad, which has a length of $602 \mathrm{~km}$ from the Garças de Minas station in Iguatama (Minas Gerais) to Angra dos Reis (Brazil, 2011).

The station in São Vicente de Minas was created in 1912, while the one in Angra dos Reis was inaugurated in 1928. The railway carried coffee, steel products and agricultural goods that came from the interior of the country to the port of Angra dos Reis. No official documents justifying the deactivation of the line were found, but it can be assumed that the economic costs were no longer supported by demand.

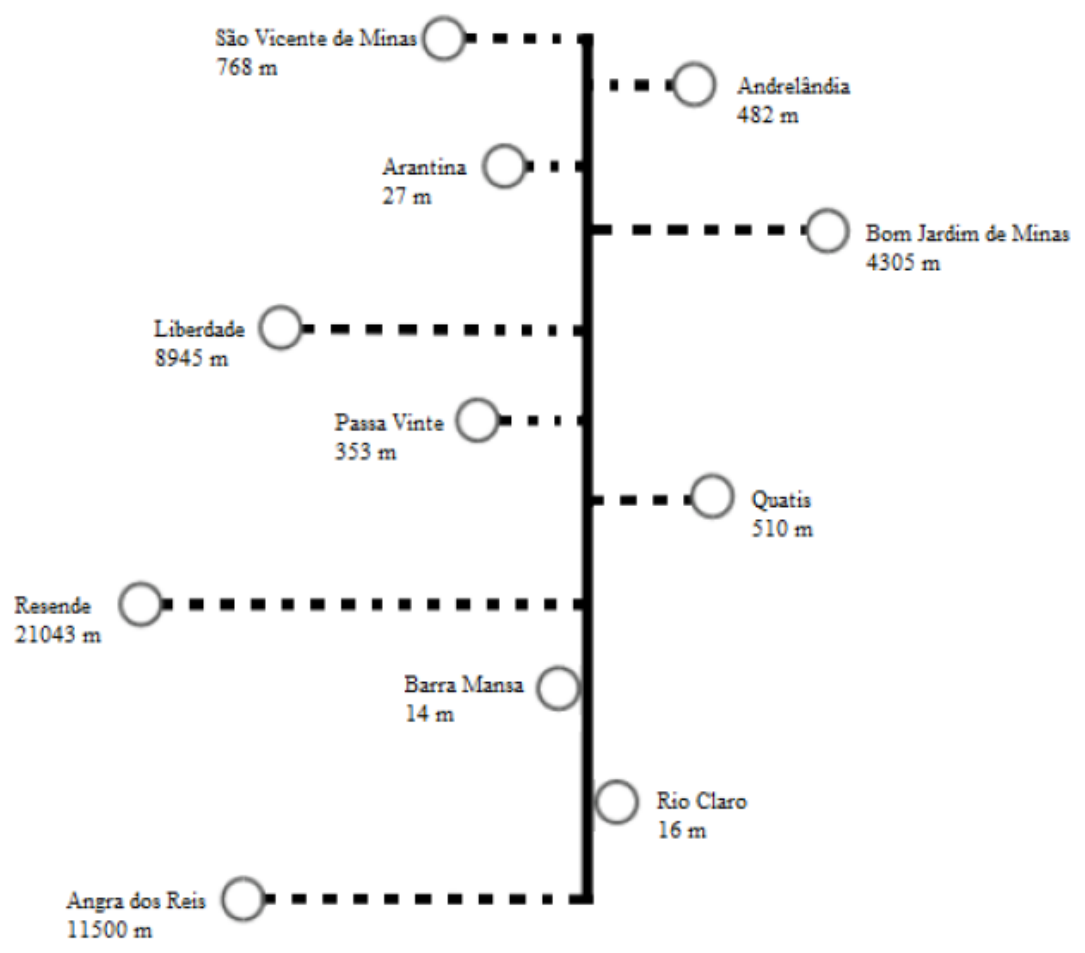

Fig. 3. Municipalities connected and distance from railway line to urban centers 


\section{Location of the railway and sections evaluated}

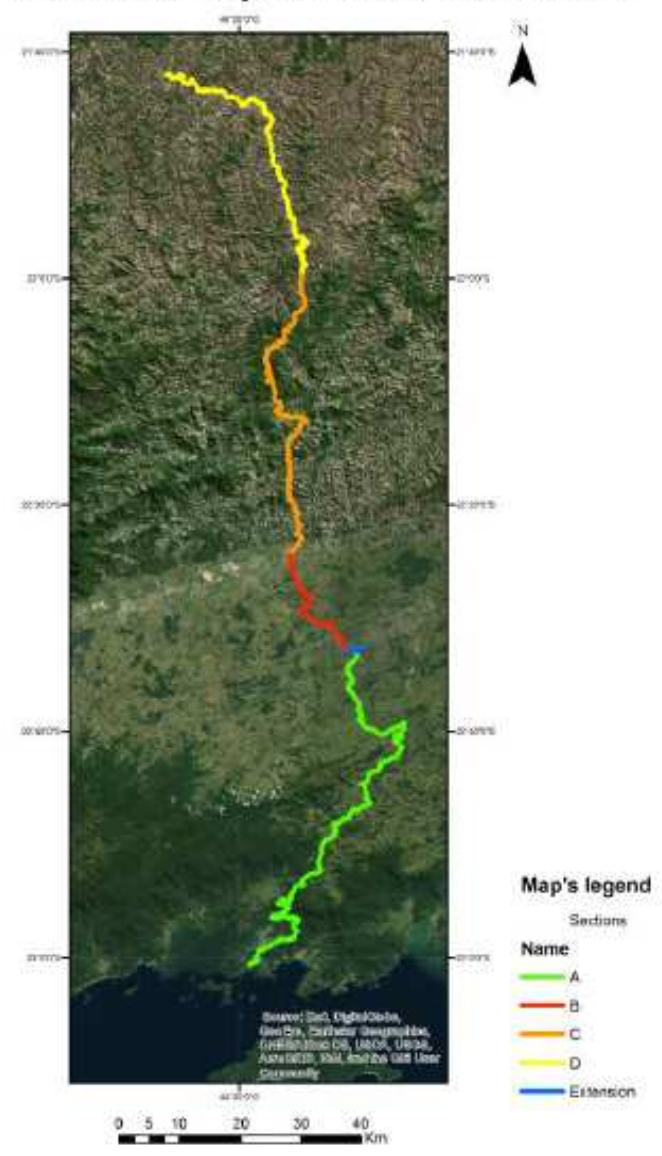

Fig. 4. Railway location

In total, this section of the railway line reaches nine municipalities and a total of 566,304 inhabitants (IBGE, 2016). According to IBGE 2013, the GDP per capita of each municipality is in excess of 250000 reais.

Figure 3 lists the municipalities connected by the railroad along with the respective distances from each city to the railroad. The railway is represented by the solid line and the distances are represented by dashed lines. Therefore, it is possible to see the proximity of the possible embarkation and disembarkation stations of the LRV to the urban centers.

For a better understanding and more comprehensive results, the railroad was separated into sections limited by the domain strip ( $15 \mathrm{~m}$ on each side of the railway). The stretches were named A, B, C, D and Extension, as seen in Fig. 4, where section A begins in Angra dos Reis at sea level and the section D ends in Vicente de Minas.

\section{Geometrical Parameters}

The points of interest for geometric study of the plot are the curves. Since QuantumGis ${ }^{\circledR}$ software does not allow superelevation analysis of aerial images, it will be considered that all curves of the trajectory have a theoretical superelevation of 160 to $170 \mathrm{~mm}$, according to Antas et al. (2010). A total of 634 curves were analyzed.

Using Equation (1) and replacing the radii of the curves obtained in AutoCad software after designing the curves that best fit the tangents, the design speed for each curve was calculated.

The lowest design speed calculated was $29.97 \mathrm{~km} / \mathrm{h}$, so all curves allow a velocity above the considered minimum of $25 \mathrm{~km} / \mathrm{h}$. The highest speed was $145.41 \mathrm{~km} / \mathrm{h}$ and the average design speeds of all curves were $52.8 \mathrm{~km} / \mathrm{h}$.

Of the 634 parameterized curves, 620 curves allow speeds above $40 \mathrm{~km} / \mathrm{h}$, whereas the remaining 14 curves have a curve radius of less than $80 \mathrm{~m}$. This result is of great interest because the LRV enables higher speeds on most curves of the route, reducing the intercity travel time and making the LRV mode of transport competitive with cars (road transport).

\section{Environmental Parameters}

Through georeferencing with the use of the software QuantumGis $\AA$, the information obtained was analyzed. Maps were generated and tables were extracted with the statistical data referring to each parameter.

The altimetry, which indicates the elevation of the land above sea level, was distributed as indicated in Table 1 and Fig. 5.

As expected, stretch A is the only one with altimetry close to zero at sea level but is mostly situated at an altitude of 301 to $600 \mathrm{~m}$.

On the other hand, stretches B and Extension are entirely in this second altitude range, while most of stretch $\mathrm{C}$ lies in the range of altitudes above $900 \mathrm{~m}$ and stretch D is entirely in this range, which corresponds to the location of the stretches of the railroad that are further away from the coastal region.

The relief amplitude map generated from the altimetric information is seen in Fig. 6. The information obtained in Table 2 shows that all the sections have low amplitude of up to $100 \mathrm{~m}$, indicating that there are no large variations in each section and the reliefs are smooth. This characteristic is sought for trains, especially passenger trains and, as seen in the geometric parameters of the track, the development of greater speeds on the curves will not need constant use of accelerators and brakes.

The slope map, which indicates slope inclinations, is shown in Fig. 7 and the slope inclinations with respective percentages for each stretch are listed in Table 3.

About $70 \%$ of the slope areas of sections B, D and Extension have slopes of up to $10^{\circ}$, while 44.83 and $33.97 \%$ of the slope areas of stretches $\mathrm{A}$ and $\mathrm{C}$, respectively, have slopes of up to $10^{\circ}$. About $30 \%$ of the slope area of stretches $\mathrm{A}$ and $\mathrm{C}$ is in the range of 11 to $20^{\circ}$ and about $20 \%$ of the slope area of stretches B, D and Extension is in this range. The section with the highest percentage area with a slope of 31 to $40^{\circ}$ is section A and there are almost no slopes of 41 to $55^{\circ}$ on the track. 


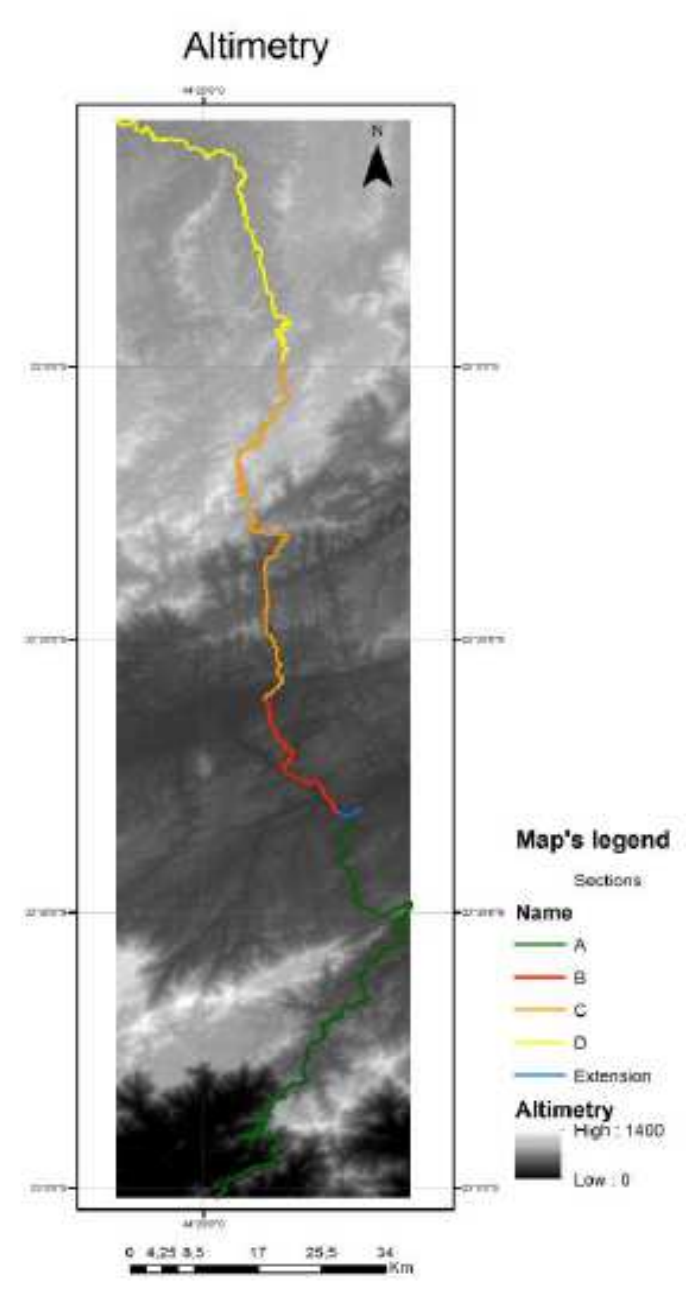

Fig. 5. Altimetry map

Table 1. Altimetry bands $(\mathrm{m})$ of each railroad stretch Section

\begin{tabular}{llllll}
\hline Altimetry & A & B & C & D & Extension \\
\hline $0-300$ & $14.94 \%$ & $0.00 \%$ & $0.00 \%$ & $0.00 \%$ & $0.00 \%$ \\
$301-600$ & $81.33 \%$ & $100.00 \%$ & $30.05 \%$ & $0.00 \%$ & $100.00 \%$ \\
$601-900$ & $3.73 \%$ & $0.00 \%$ & $17.52 \%$ & $0.00 \%$ & $0.00 \%$ \\
$901-1400$ & $0.00 \%$ & $0.00 \%$ & $52.43 \%$ & $100.00 \%$ & $0.00 \%$ \\
\hline
\end{tabular}

Table 2. Range of amplitudes (m) of each stretch of railroad Section

\begin{tabular}{llllll}
\hline Amplitude & $\mathrm{A}$ & $\mathrm{B}$ & $\mathrm{C}$ & $\mathrm{D}$ & Extension \\
\hline $0-100$ & $67.88 \%$ & $100.00 \%$ & $100.00 \%$ & $90.91 \%$ & $100.00 \%$ \\
$101-200$ & $13.94 \%$ & $0.00 \%$ & $0.00 \%$ & $1.14 \%$ & $0.00 \%$ \\
$201-300$ & $8.48 \%$ & $0.00 \%$ & $0.00 \%$ & $0.00 \%$ & $0.00 \%$ \\
$301-400$ & $4.85 \%$ & $0.00 \%$ & $0.00 \%$ & $0.00 \%$ & $0.00 \%$ \\
$>800$ & $4.85 \%$ & $0.00 \%$ & $0.00 \%$ & $7.95 \%$ & $0.00 \%$ \\
\hline
\end{tabular}

Table 3. Slope inclinations $\left(^{\circ}\right)$ by stretch of railroad Section

\begin{tabular}{llllll}
\hline Declivity & $\mathrm{A}$ & $\mathrm{B}$ & $\mathrm{C}$ & $\mathrm{D}$ & Extention \\
\hline $0-10$ & $44.83 \%$ & $71.14 \%$ & $33.97 \%$ & $77.08 \%$ & $75.68 \%$ \\
$11-20$ & $34.06 \%$ & $25.25 \%$ & $38.36 \%$ & $21.72 \%$ & $24.32 \%$ \\
$21-30$ & $16.96 \%$ & $3.61 \%$ & $25.19 \%$ & $1.20 \%$ & $0.00 \%$ \\
$31-40$ & $3.15 \%$ & $0.00 \%$ & $2.47 \%$ & $0.00 \%$ & $0.00 \%$ \\
$41-55$ & $0.99 \%$ & $0.00 \%$ & $0.00 \%$ & $0.00 \%$ & $0.00 \%$ \\
\hline
\end{tabular}

Amplitude

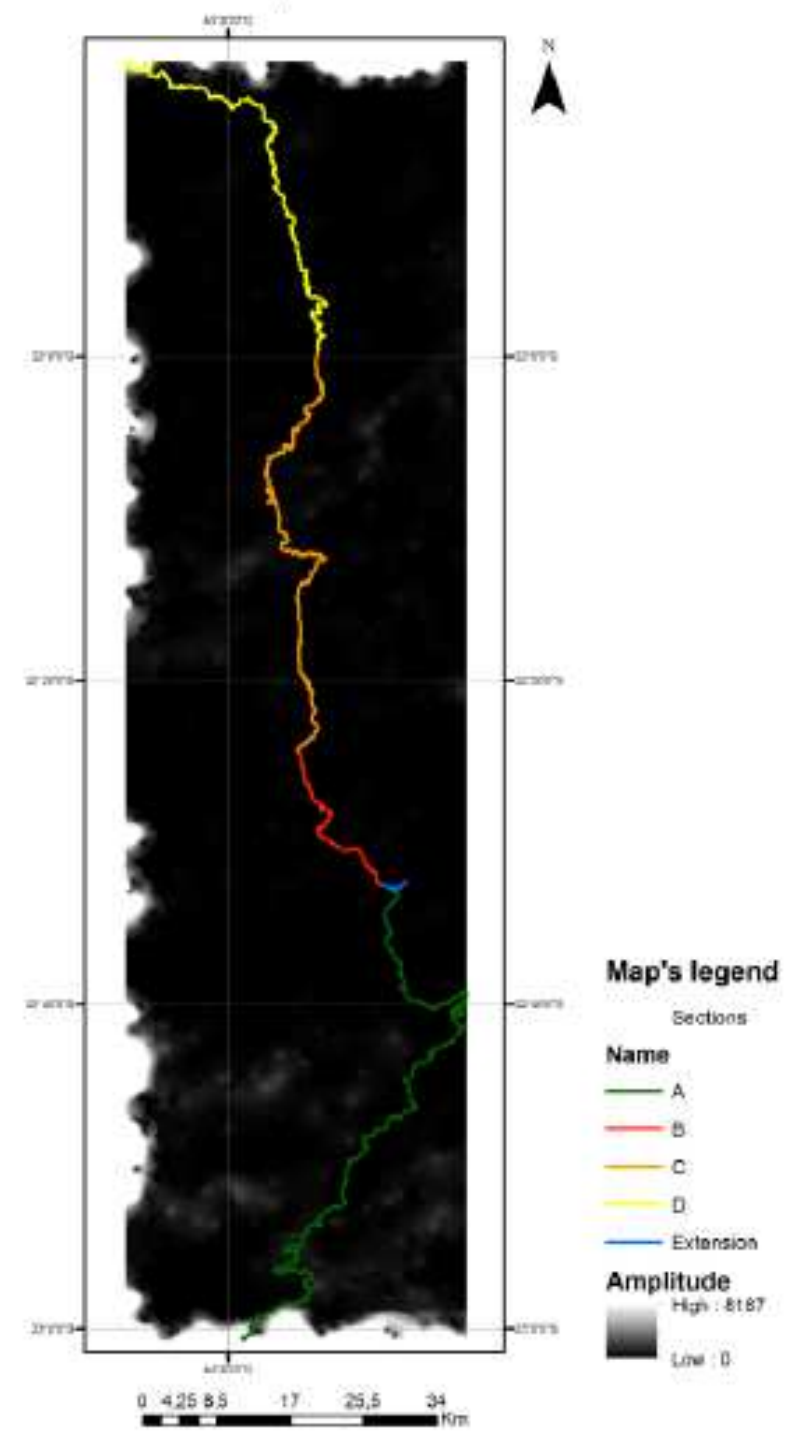

Fig. 6. Map of amplitude

Table 4. Range of susceptibility to soil slip determined by the Shalstab model

\begin{tabular}{ll}
\hline Risk & Value \\
\hline Low & $\leq-5$ \\
Medium & $>-5 \mathrm{e}<0$ \\
High & $\geq 0 \mathrm{e}<5$ \\
Very High & $\geq 5$ \\
\hline
\end{tabular}

Table 5. Susceptibility to landslide by railroad stretch Section

\begin{tabular}{llllll}
\hline Risk & $\mathrm{A}$ & $\mathrm{B}$ & $\mathrm{C}$ & $\mathrm{D}$ & Extension \\
\hline Low & $2.24 \%$ & $0.37 \%$ & $0.51 \%$ & $0.14 \%$ & $0.00 \%$ \\
Medium & $58.34 \%$ & $61.44 \%$ & $56.86 \%$ & $65.45 \%$ & $60.81 \%$ \\
High & $24.64 \%$ & $22.39 \%$ & $30.18 \%$ & $21.82 \%$ & $14.86 \%$ \\
Very High & $14.78 \%$ & $15.80 \%$ & $12.45 \%$ & $12.58 \%$ & $24.32 \%$ \\
\hline
\end{tabular}




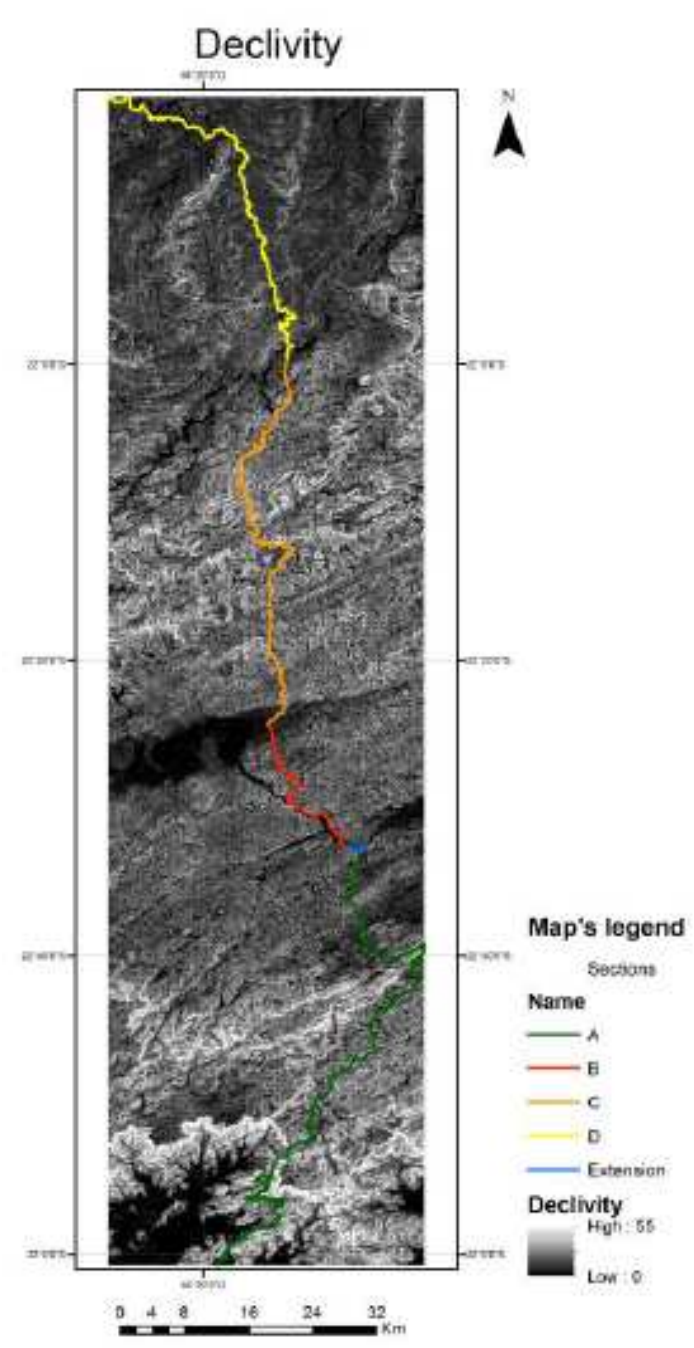

Fig. 7. Slope map

The results obtained for the slopes within the domain range are satisfactory, since they show that the risks of landslides of slope inclinations would be smaller. The analysis of the fragility of natural environments certainly depends on variables other than relief, such as soil, subsoil, land use and climate (Ross, 1994).

The last map was the one of susceptibility to sliding of the soil generated by the Shalstab model (Fig. 8). Values of risk varying from -10 to 10 were found, with the grouping being determined according to Table 4 . The percentages for each stretch varied according to what can be seen in Table 5 .

Table 5 indicates that $2.24 \%$ of the area of section A is limited by the domain range, with a low risk of soil slipping susceptibility, while less than $1 \%$ of the areas of the other stretches presents this risk. About $60 \%$ of the area of each stretch presents average risk, while $30.18 \%$ of the area of stretch $\mathrm{C}$ is at high risk and 14 to $24 \%$ of the area of the other stretches presents this level of risk.

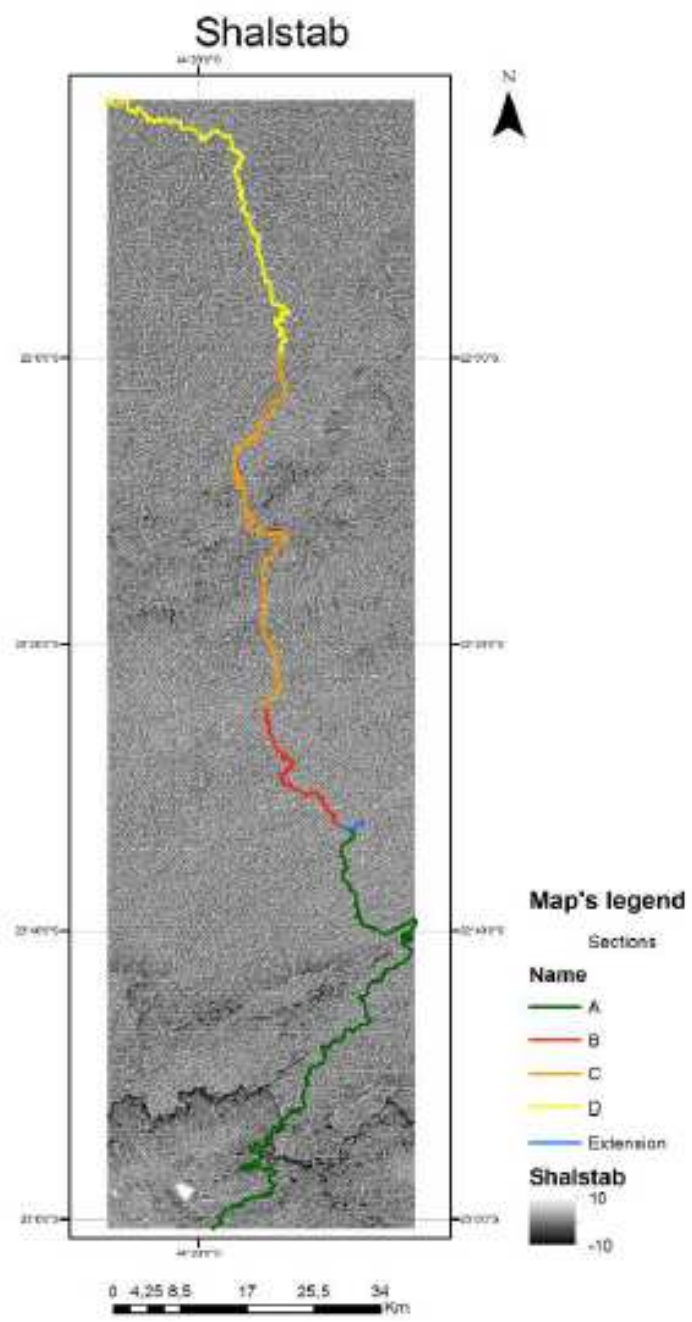

Fig. 8. Map of susceptibility to soil sliding according to the Shalstab model

Around $15 \%$ of the area of the other stretches is at very high risk, except for the Extension, of which $24.32 \%$ presents high risk. The majority of their area of all stretches is within the range of average risk of soil slip susceptibility.

\section{Discussion of Results}

The railroad portion chosen for the case study covers a good number of inhabitants, showing that it is of interest to use a more modern mode of transport of passengers within cities and between municipalities. The study must be deepened to compute the travel strategy, number of passengers and travel time, as it is a singletrack railway line that only allows one train to travel.

Since the road has already been constructed, although it is not in use, it was expected to present good geometric parameters LRV and, in fact, the results obtained for the speeds revealed that even higher speeds than those recommended are possible. 
The amplitude within the domain range shows that the relief is not steep, which generates greater comfort and safety for the passengers, enables the development of the great velocities.

The slope is not a single factor for the analysis of environmental accidents involving the morphology of the terrain, but indicates that declivities, for the most part, do not have high values, which supports the safety of the route.

Although the type of subsoil where the railroad passes is not known, the Shalstab model indicates that there are high and very high risks of soil slip susceptibility, but most of the domain range is in areas where the risk is medium.

\section{Conclusion}

From the use of the methods applied in this study, it can be concluded that the railroad, presents good characteristics for reactivation. It is known that if the LRV is to be applied, more research is required for the in situ reconnaissance of the railway in order to verify whether the superstructure remains intact and which points should be reconstituted.

In addition, the LRV is a rail transport that has several ways of working, so it is necessary to study the choice of the most suitable model, besides carrying out a study according to transport engineering.

This study focused on the initial parameters for the first evaluation of the route and it is possible to conclude that, based on the characteristics chosen, the route is favorable for reactivation although care has to be taken in areas of high susceptibility to soil slippage. In view of this, field evaluation is needed to decide the best measures to prevent accidents.

It is concluded that this method is an economic way of preliminarily evaluating the railway conditions but should not be taken as a single and invariable path for this type of research.

\section{Recognition}

The authors are grateful for the support of UFJF Federal University of Juiz de Fora.

\section{Funding Information}

This research was developed by the School of Civil Engineering, UFJF Federal University of Juiz de Fora.

\section{Authors' Contribution}

Isabelle S. Sales: Wrote the article as lead author. She developed the textual research, participated in the projection of the research plan, coordinated the numerical data and calculations, participated in the generation of the maps, generated the tables and images and wrote the article.
Gislaine Santos: Designed the plan of research and organization of the study, obtained and analyzed data, contributed to the writing of the article and carried out a critical review of the manuscript.

Jordan H. Souza: Generated maps, coordinated the numerical data and tables, designed the study plan and organization of the study and contributed to the critical review of the manuscript.

Ana Stephan: Contributed to the calculations, helped in the research plan and contributed to the critical review of the manuscript.

\section{Ethics}

This article is original and contains unpublished material. The corresponding author confirms that the other authors have read and approved the manuscript and that no ethical problems are involved.

\section{References}

Alouche, P., 2007. Corredores urbanos de transporte para altas demandas. Trabalho apresentado no Seminário: Soluções Integradas de Transporte, Porto Alegre.

Alouche, P., 2012. O VLT Estrutura a Cidade: entrevista com Peter Alouche. Portal Mobilize Brasil.

Amaral, A., 1957. Manual de engenharia ferroviária. Globo.

Antas et al., 2010. Estradas: projeto geométrico e de terraplanagem. Interciência, Rio de Janeiro.

Araújo, P., 2004. Análise de suscetibilidade a escorregamentos: uma abordagem probabilística. Universidade Estadual Paulista, Rio Claro.

Cao, J. 2013. The association between light rail transit and satisfactions with travel and life: Evidence from Twin Cities. Transportation, 40: 921-933.

Confederação Nacional do Transporte (CNT), 2013. O sistema ferroviário brasileiro. Brasília.

Confederação Nacional do Transporte (CNT), 2016. Transporte metroferroviário de passageiros. Brasília.

De Carvalho, M., 1973. Curso de estradas: estudos, projetos e locação de ferrovias e rodovias, $1^{\circ}$ volume. Científica, Rio de Janeiro.

Ferbrache, F. and R. Knowles, 2017. A critical review of light rail impacts on city image and quality. Geoforum, 80: 103-113.

Finger, A., 2013. Um século de estradas de ferro: Arquiteturas das ferrovias no Brasil entre 1852 e 1957. Universidade de Brasília, Brasília.

Hara, L.T., 1998. Técnicas de Apresentação de Dados em Geoprocessamento. Instituto Nacional de Pesquisas Espaciais, São José dos Campos.

Hobsbawn, E., 1977. A era das revoluções 1789-1848, $33^{\mathrm{a}}$ edição. Paz e Terra. 
Instituto Brasileiro de Geografia e Estatística (IBGE), 2016.

Instituto Brasileiro de Geografia e Estatística, Conselho Nacional de Geografia (IBGE), 1954. Serviço Gráfico do instituto brasileiro de geografia e estatística. I centenário das ferrovias brasileiras. Rio de Janeiro.

Lima, L., 2003. A máquina, tração do progresso: memórias da ferrovia no oeste de minas: entre o sertão e a civilização 1880-1930. Universidade Federal de Minas Gerais, Belo Horizonte

Luz, N.V., 1978. A Luta pela Industrialização do Brasil, $2^{a}$ edição. Alfa Ômega, São Paulo.

Mauro, J and J. Lollo, 2004. Uso da Técnica de Avaliação do Terreno para a Elaboração de Carta de Susceptibilidade à Erosão na Bacia do Prosa Campo Grande, MS. Revista Brasileira de Recursos Hídricos, 9: 23-38.

Motta, M., 2013. O veículo leve sobre trilhos: considerações sobre os seus atributos como justificativa para a sua implantação. Universidade Federal do Rio de Janeiro, Rio de Janeiro.
Oliveira, U., 2009. Proposta de Implantação de Sistema de Transporte de Passageiros do Tipo Monotrilho na Região Metropolitana de Vitória. Instituto Federal do Espírito Santo (IFES).

Picanço, F., 1887. Revista Estradas de Ferro, n. 34, ano 3. Rio de Janeiro.

Ross, J. L. S., 1994. Análise empírica da fragilidade dos ambientes naturais e antropizados. Revista do Departamento de Geografia, pp: 63-74.

Seabra, 2010. Mapeamento dos sistemas de relevo da bacia hidrográfica do rio São João. III Simpósio Brasileiro de Ciências Geodésicas e Tecnologias da Geoinformação, Recife, pp: 001-004.

Silva, D., 2006. Aplicação do modelo Shalstab na previsão de deslizamentos em Petrópolis. Universidade Federal do Rio de Janeiro, Rio de Janeiro

Vuchic, V.K., 2012. Urban public transportation systems. 